\title{
CIGANOS PORTUGUESES Escola e mudança social
}

Maria Manuela Mendes

Instituto Universitário de Lisboa (ISCTE-IUL), Centro de Investigação e Estudos de Sociologia (Cies_Iscte) e FAUL, Universidade de Lisboa, Lisboa, Portugal

Olga Magano

Universidade Aberta; Instituto Universitário de Lisboa (ISCTE-IUL), Centro de Investigação e Estudos de Sociologia (Cies_Iscte), Lisboa, Portugal

Ana Rita Costa

Instituto Universitário de Lisboa (ISCTE-IUL), Centro em Rede de Investigação em Antropologia (CRIA), Lisboa, Portugal

\begin{abstract}
Resumo O cumprimento da escolaridade obrigatória, o sucesso e o controlo do abandono escolar estão longe de ser metas atingidas em Portugal para as crianças e jovens ciganos. Atualmente está mais clara a importância da escolarização, seja do ponto de vista do estado, regulador do acesso de todos ao sistema de ensino público, seja por parte das famílias, que reconhecem a sua importância como recurso essencial para uma cidadania efetiva. Neste artigo, através de uma abordagem etnográfica, são evidenciadas, por um lado, a continuidade de reprodução de desigualdades sociais em relação aos ciganos portugueses e, por outro, os processos de mudança em curso que mostram que, face à escola, os ciganos experienciam desafios, enfrentando mudanças provindas de dentro e de fora da escola.
\end{abstract}

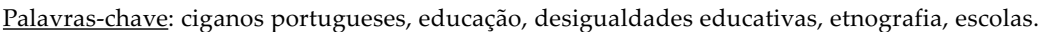

Portuguese Ciganos: school and social change

Abstract Compliance with compulsory schooling, school success and control of school drop-out are far from being achieved targets in Portugal for Portuguese Roma (Ciganos) children and youth. The importance of schooling is now clearer, from the point of view of the State, which regulates the access of all to the public education system, or from the families who recognize its importance as an essential resource for effective citizenship. In this article, from an ethnographic approach, on the one hand, the continuity of reproduction of social inequalities in relation to Ciganos will be evidenced, and, on the other hand, the ongoing processes of change that show that, in relation to the school, Ciganos experience challenges, facing changes from within and outside of school.

Keywords: Portuguese Ciganos/Gypsies, education, educational inequalities, ethnography, schools.

\section{Gitans portugais: changement scolaire et social}

Résumé L'accomplissement de la scolarité obligatoire, la réussite et le contrôle du décrochage scolaire sont loin d'être des objectifs atteints au Portugal pour les enfants et les jeunes gitans. L'importance de la scolarité est maintenant claire, que ce soit de la part de l'État, qui réglemente l'accès de tous au système d'éducation publique, ou de la part des familles, qui reconnaissent son importance en tant que ressource essentielle pour une citoyenneté effective. Dans cet article, à travers une approche ethnographique, la continuité de la reproduction des inégalités sociales par rapport aux gitans portugais est mise en évidence, d'une part, et d'autre part, les processus de changement en cours qui montrent que, face à l'école, les gitans font face aux changements de l'intérieur et de l'extérieur de l'école.

Mots-clés: gitans portugais, éducation, inégalités éducatives, ethnographie, écoles. 
Resumen La finalización de la escolarización obligatoria, el éxito y el control de abandono escolar están lejos de ser hitos conseguidos en Portugal para los niños y jóvenes gitanos. Actualmente está más claro la importancia de la escolarización, sea por parte del Estado, regulador del acceso de todos al sistema de enseñanza pública, sea por parte de las familias, que reconocen su importancia como recurso esencial para una ciudadanía efectiva. En este artículo, a través de un enfoque etnográfico se pone de manifiesto, por un lado, la continuidad de la reproducción de las desigualdades sociales en los gitanos portugueses y, por el otro, los procesos de cambio en curso que demuestran que los gitanos viven algunos retos en la escuela, enfrentando cambios provenientes de dentro y fuera de la escuela.

Palabras-clave: gitanos portugueses, educación, desigualdades educativas, etnografía, escuelas.

\section{Introdução}

Em Portugal a escolarização da maior parte dos ciganos continua a ser um processo difícil de concretizar. Não obstante a profusão de políticas sociais e educativas implementadas desde 1974, a maioria desta população continua a apresentar baixos níveis de escolaridade, altas taxas de insucesso e de abandono escolar, bem como poucos diplomados com o ensino superior. Estudos disponíveis indicam que os ciganos portugueses apresentam baixos níveis de escolaridade obrigatória e uma taxa de abandono escolar elevada (Bastos, Correia e Rodrigues, 2007; Mendes, 2007; Nicolau, 2010, Mendes, Magano e Candeias, 2014; Magano e Mendes, 2016). A dimensão de género também tem uma importante influência na escolaridade. As mulheres ciganas têm um nível de escolaridade, em regra, mais baixo do que os homens, sendo raros os casos em que ultrapassam o ensino básico (idem). É uma situação transversal aos ciganos que têm vários modos de vida, mesmo entre os ciganos ditos "integrados" (sob o ponto de vista do exercício de uma profissão por conta de outrem e sem fazerem "modo de vida cigano" ${ }^{1}$ ), em que as mulheres têm menos anos de escolaridade do que os homens ciganos (Magano, 2010).

Dados recolhidos em 2014, no âmbito do Estudo Nacional sobre as Comunidades Ciganas (ENCC), em que foram inquiridas 1599 pessoas, mostram que 1/3 dos inquiridos nunca frequentou a escola ou não foi além do $1 .^{\circ}$ ciclo do ensino básico e apenas 2,8\% possuíam um diploma do ensino secundário e/ou superior (Mendes, Magano e Candeias, 2014), em contrapartida, 19,2\% da população portuguesa detinha o ensino secundário e 16,5\% o ensino superior (Pordata, 2014). Estes níveis de escolaridade não se distribuem de forma homogénea e uniforme pelo país, sendo possível evidenciar padrões de caráter regional. Com efeito, mais de

$1 \mathrm{O}$ "modo de vida cigano" envolve um conjunto de valores e práticas quotidianas, historicamente situadas, associadas à vida familiar, ao trabalho, ao consumo e ao lazer que, embora coexistam entre os ciganos diferentes modos de vida, em particular, estamos a fazer referência à tradicionalidade, denotando-se uma forte demarcação dos papéis de género, práticas de trabalho autónomas e mais ligadas ao comércio ambulante, pela forte valorização da lei e tradições ciganas e relações e práticas endogâmicas interétnicas. 
metade (54\%) dos ciganos residentes na região Norte possui escolaridade ao nível do 1. ․ ciclo (completo ou incompleto), no Centro denota-se uma maior expressão daqueles que não sabem ler nem escrever (28\%), situação que se agrava no Alentejo e no Algarve, onde tal valor atinge os 38\% e 39\%, respetivamente. Dados mais recentes revelam ainda que, em relação ao ano letivo de 2016/2017, 48\% dos alunos ciganos acumulavam uma ou mais retenções (DGEEC, 2018).

Em termos de escolaridade, subsistem diferenças claras e significativas entre os ciganos portugueses e a população em geral. Estas diferenças são, antes de mais, reflexo de velhas e conhecidas formas de desigualdade estrutural e expressas em níveis de desfavorecimento assinaláveis face aos demais cidadãos, sobretudo no acesso e permanência na escola, no acesso à formação profissional, no acesso ao emprego e à habitação (mercado formal) e no acesso aos serviços públicos e à justiça (Mendes, 2007; Magano e Mendes, 2014). No que se refere ao sistema educativo, os eixos explicativos para esta situação organizam-se entre perspetivas estruturalistas (Bourdieu e Passeron, 1970) e as explicações culturalistas. De acordo com as perspetivas estruturalistas, os desempenhos e os percursos escolares dos estudantes ciganos são em grande medida determinados pelo capital cultural e pela pertença de classe das suas famílias, mas também o funcionamento e organização da instituição escolar contribui para reforçar as desigualdades. No que se refere às explicações culturalistas, elas centram-se na idiossincrasia da cultura cigana e da socialização familiar e intragrupal enquanto obstáculo ao sucesso escolar, sendo ainda de ressaltar a teoria ecológico-cultural de Ogbu (1981), de feição multinível e que se focaliza na análise da história dos contactos entre uma dada minoria e a maioria, o seu status atual e a resposta coletiva e adaptativa que a minoria revela perante condições estruturais (Ogbu, 1981; Abajo e Carrasco, 2011).

Neste texto em particular, parece justificado ter como ponto de focagem, por um lado, a análise dos processos de escolarização da população cigana e, por outro, procurar discernir conexões entre estes e outros processos mais amplos de mudança social. Esta análise alicerça-se nos resultados de uma pesquisa qualitativa ${ }^{2}$ que decorreu entre meados de 2013 e finais de 2015 e que teve por finalidade identificar e compreender alguns dos fatores-chave para a continuidade escolar e sucesso educativo dos ciganos em contextos educativos plurais e marcados pela interculturalidade. Concretamente, esta análise centra-se num estudo de cariz etnográfico, levado a efeito num bairro e numa escola localizados no município de Lisboa, em que se procurou analisar os quotidianos e cenários escolares, mas também as relações entre alunos, entre professores e alunos, e entre escolas e famílias. Pretendeu-se, deste modo, resgatar um olhar de perto e de dentro (Magnani, 2002), articulando perspetivas e olhares distintos, escalas e contextos vivenciais, nomeadamente territórios de residência/bairro e escola.

2 "Factores-Chave para o Sucesso e Continuidade dos Percursos Escolares dos Ciganos. Indivíduos, Famílias e Políticas Públicas", financiado pela Fundação para a Ciência e a Tecnologia, Ref. PTDC/IVC-PEC/4909/2012, que decorreu nas áreas metropolitanas de Lisboa e Porto. 


\section{Contexto e metodologia de investigação}

A metodologia adotada neste projeto de investigação é de caráter qualitativo e envolveu a combinação de várias técnicas de recolha de dados, com ênfase na abordagem etnográfica. A etnografia, enquanto modo de produção de conhecimento que descreve uma realidade social particular, permite um conhecimento em profundidade de certas problemáticas, por via do seu potencial hermenêutico e epistemológico (Denzin e Lincoln, 2000 [1994]; Silva, Sacramento e Mendonça, 2015). O envolvimento ativo do pesquisador revela-se um poderoso instrumento de pesquisa, gerando formas de interação entre o investigador e o informante, o que proporciona a base para a coconstrução de significados e conhecimentos que são social e espacialmente situados, sendo, então, de realçar a importância da espacialidade na pesquisa etnográfica (Hammersley e Atkinson, 2007; Brockmann, 2011). O recurso à etnografia implica, antes de mais, uma estratégia de abordagem ao terreno

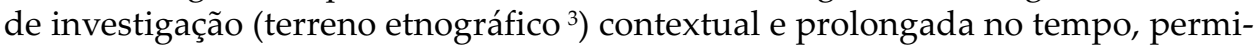
tindo que se estabeleça um contacto próximo com as pessoas que se pretende conhecer e com as suas mundividências. As qualidades desta abordagem têm sido reconhecidas, nomeadamente, nos estudos com populações ciganas (Lopes, 2008; Sigona, 2009; Casa-Nova, 2009).

No presente estudo, foi importante primeiro conhecer as pessoas e os seus espaços e redes de socialização, pela permanência quotidiana nos bairros em que habitavam. Só posteriormente se avançou com a realização de trabalho de campo em meio escolar.

As escolas dos agrupamentos escolares (AE) onde foi realizado o estudo localizam-se nos territórios em que decorreu a pesquisa etnográfica. Trata-se de áreas urbanas caraterizadas por uma marcada presença de famílias ciganas portuguesas aí residentes há várias gerações. Na área metropolitana de Lisboa, a investigação centrou-se em três bairros, localizados em diferentes municípios (Loures, Amadora e Lisboa), que nesta análise optamos por não identificar.

Embora os trabalhos preparatórios e as visitas às escolas tenham tido início ainda no ano letivo de 2013/2014, o trabalho de campo etnográfico em meio escolar apenas decorreu no 1.. período do ano letivo de 2014/2015, entre setembro e dezembro de 2014, estendendo-se para os meses de janeiro e fevereiro de 2015. Durante estes meses, permanecemos e observámos os espaços comuns das escolas (recreios, cantinas, bares e outros espaços de refeição, átrios, corredores e outros locais de permanência e circulação), observámos os tempos letivos (aulas) e não

3 A expressão terreno e/ou território etnográfico remete para o complexo contexto socioespacial em que desenvolvemos a investigação etnográfica, e na sua delimitação foram consideradas várias dimensões e escalas de observação, envolvendo os espaços habitacionais das famílias ciganas, os circuitos quotidianos protagonizados pelas pessoas ciganas, nomeadamente as escolas em que as crianças e jovens em idade escolar estão matriculados. Esta conceção alargada e abrangente tem por suporte o trabalho desenvolvido por Fernandes (1998), no que se refere ao conceito de "territórios psicotrópicos", e também por Cordeiro, Batista e Costa (2003), no que se refere ao conceito traçado sobre etnografias urbanas em que o terreno é entendido como uma teia de (inter)relações que se desenvolvem em diversos espaços. 
letivos (por exemplo, as atividades de enriquecimento curricular) e participámos em diversos eventos. Ao longo do trabalho de campo foi possível conviver e conversar de forma próxima com as crianças e jovens ciganos, professores, funcionários e técnicos de intervenção que atuavam no território e, também, com as famílias dos alunos. Já conhecíamos algumas famílias, o que veio a facilitar a nossa integração nas escolas.

A par do trabalho de campo etnográfico em cinco escolas públicas distribuídas por três $\mathrm{AE}$, realizaram-se quatro grupos focais e 36 entrevistas semiestruturadas, a homens e mulheres, a fim de se apreender conceções e práticas na área da educação e temáticas particulares a cada território e respetivas escolas, a atores escolares, nomeadamente professores, coordenadores de níveis de escolaridade e outros técnicos que trabalhavam na escola, considerados como relevantes para compreender melhor as observações que íamos registando.

Nas escolas selecionadas acompanhámos de modo particular sete turmas, ${ }^{4}$ que foram identificadas em conjunto com a direção de cada $\mathrm{AE}$ como representativas da realidade escolar dos alunos ciganos de ambos os sexos. Uma vez que um dos objetivos do estudo era a avaliação dos impactos das políticas públicas na continuidade dos percursos escolares dos estudantes ciganos, um dos nossos requisitos era o de acompanhar a maior diversidade possível de ofertas educativas existentes nas diferentes escolas. Por essa razão, para além de turmas do designado ensino regular, realizámos trabalho de campo com turmas abrangidas por medidas de diversificação da oferta formativa.

No presente artigo, iremos apenas abordar uma das escolas que integram o $\mathrm{AE}$ que tem maior dimensão, e onde se regista, globalmente, uma maior presença de crianças e jovens ciganos, tendo-se aqui efetuado entrevistas semiestruturadas e dois grupos focais, um com docentes e técnicos de educação e outro com familiares dos alunos. Em particular, esta análise focaliza-se sobre uma turma do 3.․a ano do 1. - ciclo do ensino básico, composta por um elevado número de alunos ciganos. Antes de avançarmos, faremos uma breve caraterização do território etnográfico no qual se localiza a escola em análise.

\section{Território etnográfico: entre o bairro e a escola}

O terreno de investigação localiza-se numa freguesia periférica do município de Lisboa, sendo o bairro onde se centrou o estudo o terceiro mais populoso da freguesia. De acordo com os censos (INE, 2011), residem no bairro aproximadamente 1700 pessoas, maioritariamente de nacionalidade portuguesa, estimando-se que entre $20 \%$ a $30 \%$ sejam de origem cigana? Pela nossa observação, com base no número de habitações,

4 Uma turma do $3 .{ }^{\circ}$ ano, duas turmas do $5 .^{\circ}$ ano, uma turma de percursos curriculares alternativos, uma turma do ensino vocacional e duas turmas do "PIEF".

5 Os números apresentados são estimativas com base em dados cedidos pelas entidades que intervêm no bairro. Não é possível conhecer o número exato de pessoas ciganas a residir no bairro, uma vez que tem sido reiteradamente afirmado que a Constituição Portuguesa não permite a recolha destes dados, embora essa recolha seja uma recomendação que a ONU tem feito regularmente ao país. 
estima-se que viverão no bairro aproximadamente 400 pessoas ciganas, entre adultos e crianças. De acordo com Santos et al. (2008) trata-se de um dos bairros do município com um maior número de famílias ciganas realojadas.

A maioria dos residentes detinha o $1 .^{\circ}$ ciclo do ensino básico e encontrava-se sem atividade económica (INE, 2011). O bairro - cuja construção teve início antes de 1974 e se destinava a alojar profissionais da então Direção-Geral de Segurança (DGS), um organismo português de polícia de repressão e prevenção criminal que funcionou entre 1969 e 1974, e que veio substituir a Polícia Internacional e de Defesa do Estado (PIDE) - foi ocupado no período imediatamente a seguir ao 25 de Abril de 1974. Algumas famílias ciganas que conhecemos participaram nestas primeiras ocupações. Entre 1975 e 1978, o projeto inicial foi alterado com vista a uma densificação residencial, ficando com as suas atuais 602 habitações, distribuídas por 65 lotes. Embora permaneça maioritariamente de habitação social, cerca de 150 habitações foram compradas pelos residentes e são agora propriedade privada, estando as restantes sob gestão da Câmara Municipal de Lisboa.

Apesar da sua localização periférica na freguesia, o bairro dispõe de um privilegiado sistema de vistas sobre o rio Tejo, situando-se nas suas imediações um parque florestal de grandes dimensões, alguns monumentos nacionais e outros com elevado valor patrimonial.

Contudo, pela sua configuração e localização, o bairro encontra-se isolado, fechado sobre si e, de certo modo, segregado em relação à freguesia. Ou seja, estamos perante um espaço caraterizado por uma configuração espacial que promove um certo fechamento social dos residentes neste território, prefigurando-se como uma espécie de "aprisionamento" do qual é difícil as pessoas se desenredarem (Wacquant, 2014). A área residencial que o circunda encontrava-se muito degradada, apesar do elevado potencial arquitetónico, contribuindo para uma imagem menos positiva do território. Nos bairros circundantes também residem muitas famílias ciganas e, apesar de existir uma certa desconexão espacial, verifica-se a existência de relações familiares e de amizade (e também de conflito) entre pessoas ciganas residentes na freguesia de inscrição do bairro em análise.

Durante o trabalho de campo, o bairro foi alvo de uma intervenção urbana que visou melhorar a sua "imagem" e que deriva em grande medida de programas e políticas locais que procuram dar uma renovada visibilidade a bairros e espaços esquecidos pela intervenção municipal. Esta nova dinâmica tem sido, em parte, proporcionada pela autarquia e por alguns ex-estudantes e professores da Faculdade de Arquitetura, por via de diversos projetos de requalificação. Contudo, muitos moradores expressavam sentimentos de desilusão, uma vez que, à data, os melhoramentos eram apenas exteriores e não visavam o interior das suas residências que, na sua generalidade, apresentavam elevados níveis de degradação.

No que se refere à escolaridade e frequência escolar é importante destacar que foi neste território que conhecemos pessoas com escolaridade mais elevada, tendo dois homens completado o $12 .^{\circ}$ ano do ensino secundário. Quanto às crianças ciganas, constatámos que estavam integradas nas escolas afetas à sua área de residência. Já no caso dos jovens, verificámos que continuavam a persistir situações de absentismo escolar, tendo-nos sido transmitido que esta situação tinha registado uma franca 
evolução em relação a um passado próximo, havendo cada vez mais jovens ciganos, rapazes e raparigas, a frequentarem a escola. Estes resultados estão em linha com os que se conhecem em relação a outros territórios e também a nível nacional (Mendes, Magano e Candeias, 2014).

Constatámos, também, que muitas famílias, por sua iniciativa, estavam a inscrever as suas filhas adolescentes na modalidade de ensino a distância (ED), ${ }^{6}$ sobretudo a partir do $2 .^{\circ}$ e $3 .^{\circ}$ ciclos de escolaridade. Neste território em particular, as famílias tiveram conhecimento desta modalidade de ensino por via de pastores de igrejas evangélicas que frequentavam, também eles ciganos, bastando para o efeito alegarem que eram "feirantes" e "pastores da Igreja". Para as famílias esta opção era entendida como uma forma possível de proteger as suas filhas e de fazer respeitar a sua tradição, sem a interferência da escola e das assistentes sociais. Os pais com quem conversámos referiram que tinham gosto e que apoiavam a continuidade do percurso escolar das filhas por esta via, alguns salientaram que eles próprios ou irmãos/irmãs costumavam dar algum apoio ao estudo para incentivar este progresso. No entanto, a maioria das jovens que frequentava o ED referiu sentir-se desapoiada e desmotivada. Ao longo do trabalho de campo, neste e noutros territórios, não nos foi possível identificar nenhum caso de escolaridade mais prolongada, embora a coordenadora do ED, numa entrevista por nós realizada, tenha sinalizado um caso em que uma aluna cigana estaria a frequentar o $11 . \stackrel{\circ}{ }$ ano.

Globalmente, no bairro em análise foi difícil encontrar jovens com percursos escolares mais longos (entre o 9.. ano e o 12.. ano), nomeadamente raparigas. Ora, sendo a escolaridade obrigatória de 12 anos, a não conclusão do secundário implica a reprodução da situação de abandono e/ou insucesso escolar, mesmo quando atualmente já se realizam mais anos de escolaridade. Continua a registar-se um grande desfasamento entre o que está regulamentado e a realidade vivida.

Um outro aspeto a destacar é o facto de, neste bairro, muitas crianças estarem integradas no ensino pré-escolar e de esta prática acontecer há pelo menos duas gerações, o que certamente se deve à longa e múltipla intervenção social no bairro, nomeadamente no que se refere à presença de estruturas educativas e de apoio escolar.

Em termos de ocupação profissional, e embora o trabalho da venda ambulante tenha uma grande expressividade, este foi o território onde conhecemos um maior número de homens ciganos com trajetórias de trabalho por conta de outrem (na área da construção civil, em fábricas, na pesca, na restauração, em escolas, entre outros), encontrando-se muitos em situação de desemprego durante a realização do estudo. Em algumas famílias, estas trajetórias de trabalho eram transversais às várias gerações. Já no caso das mulheres ciganas, não identificámos nenhuma que exercesse uma atividade profissional diferente da venda ambulante, embora muitas tenham

6 “O Ensino a Distância (ED) é uma oferta educativa e formativa para os $2 .^{\circ}$ e $3{ }^{\circ}$ ciclos do ensino básico e do ensino secundário, complementar das outras ofertas curriculares existentes nestes níveis de ensino. OED funciona através de uma plataforma digital, constituída por salas de aula virtuais, organizadas por público-alvo, ano e ciclo de escolaridade, com recurso a formas de trabalho síncronas e assíncronas" (http://www.dge.mec.pt/ensino-distancia-0, consultado em 27 de outubro de 2017). 
referido que gostariam de trabalhar em lojas ou nas limpezas. Algumas mulheres procuravam ativamente trabalhos nestas áreas, mas entendiam que o facto de "parecerem ciganas" seria um obstáculo à sua contratação, procurando, por essa razão, ocultar a sua identidade étnica. Mesmo as pessoas que trabalhavam por conta de outrem costumavam exercer a venda ambulante em feiras e mercados que decorriam ao fim de semana. Para além de ser uma fonte de rendimento adicional, a possibilidade de realizar estes trabalhos era percebida com grande satisfação e orgulho, sendo uma forma de reatualizarem práticas tradicionais e de assim estarem vinculados a contextos e espaços de sociabilidade intraétnica, numa demonstração de que é possível a conjugação de atividades ciganas tradicionais com as exigências laborais das sociedades contemporâneas, sem que isso leve à perda de identidade cigana (Magano, 2010).

Em relação às fontes de rendimento, as famílias contactadas auferem, ou auferiram durante um período, do rendimento social de inserção, declarando que esta prestação social foi e é muito importante para equilibrar o orçamento familiar e garantir a subsistência do grupo familiar, particularmente numa altura em que em que a venda era muito incerta e pouco rentável.

Quanto à convivialidade entre os moradores ciganos e os restantes moradores, apesar do longo tempo de residência, de frequentarem os mesmos espaços comerciais no bairro e de existirem algumas relações de vizinhança, os relacionamentos eram marcados por raras e circunscritas situações de convívio interétnico entre adultos, menos visíveis entre crianças.

\section{O agrupamento e a escola}

A freguesia onde se localiza o bairro apresenta uma população bastante heterogénea, aspeto que se reflete na população escolar que frequenta as escolas dos dois $\mathrm{AE}$ aqui existentes. Os dois $\mathrm{AE}$ integram escolas frequentadas pelas crianças e jovens das famílias ciganas residentes do bairro em estudo e, num passado próximo, por muitos dos seus pais e familiares.

Pese embora o facto de os dois AE tenham população em situação socioeconómica vulnerável é, sobretudo, no AE onde realizámos a pesquisa que se concentram as famílias com rendimentos mais baixos. É importante salientar que a nossa intenção inicial era realizar trabalho de campo em ambos os AE, mas apenas neste último caso obtivemos autorização em tempo útil para avançar com a investigação.

No ano letivo de 2013/2014, o AE em análise era frequentado por 1412 alunos. Desses, 855 (correspondendo a 61\% da população escolar) eram beneficiários da Ação Social Escolar, uma medida destinada aos alunos de agregados familiares cuja situação económica determina a necessidade de uma comparticipação financeira, o que evidencia a fragilidade económica desta população.

Informalmente foi-nos transmitido que frequentariam o AE cerca de uma centena de crianças e jovens ciganos, estando a maioria integrada numa escola do $1 .^{\circ}$ ciclo do AE e na escola-sede frequentada por todos os alunos do $2 .^{\circ}$ e $3 .^{\circ}$ ciclos (5.. .00 a $9 .^{\circ}$ ano de escolaridade) e ensino secundário (10. ao 12.ำ ano de escolaridade). 
Em 2011, o relatório produzido no âmbito da avaliação externa das escolas aponta como aspetos a melhorar por parte do AE o acentuado absentismo de alguns alunos, destacando o caso dos alunos ciganos. Esta situação, embora tivesse evoluído positivamente, continuava a persistir, nomeadamente, a partir do $2 . . . \mathrm{e}$ 3.. ciclos.

\section{Etnografando com e na escola}

Uma das principais diferenças entre a linha etnográfica e outras pesquisas qualitativas em contexto de sala de aula é que estas procuram a natureza causal dos fenómenos, enquanto a etnografia procura evidenciar a natureza processual, ou seja, a forma como as relações são construídas numa sala de aula, em particular, ou nas interações interpessoais que se estabelecem no contexto escolar e social (Mattos, 2011: 67). Uma outra potencialidade das etnografias em meio escolar consiste em assumirem uma abordagem crítica, revelando vozes e protagonistas que por vezes são silenciados (Feinberg, 2015), permitindo apreender relações de poder de caráter assimétrico que subsistem entre ciganos e sociedade maioritária (Setti, 2015). Nesta pesquisa, a opção pela utilização da etnografia veio permitir a apreensão de valores diferentes e até conflituantes, proporcionando o acesso a significados compartilhados e associados a práticas diversas (relacionadas com as limitações estruturais, as diferentes posições e apropriações dos sujeitos, entre outras questões) (Cerletti, 2011). Permitiu-nos, ainda, conhecer não só as perspetivas dos técnicos e docentes, mas também das crianças e das respetivas famílias sobre a escola e sobre a escolarização.

Importa realçar que, para as famílias entrevistadas, a frequência escolar nos primeiros anos de ensino, mais do que uma obrigação, é percebida como um direito de cidadania. As famílias mostram uma atitude pragmática face à escola enquanto estratégia de adaptação e de interconhecimento inegável entre ciganos e não ciganos, como ilustra o próximo testemunho.

A escola, ajudou na altura, muito. Porque começou a aceitar, já começaram a aceitar mais o cigano. E foi importante, porque através da escola começaram, o cigano começou-se a integrar mais também com outras culturas, com outras maneiras [homem, 40-64 anos, 6. $\stackrel{\circ}{ }$ ano, vigilante de obras].

Os pais estão cientes de que uma cidadania mais inclusiva passa por um maior investimento em torno da escolaridade, o que proporcionará aos jovens mais oportunidades de reconhecimento e de promoção social. No entanto, na escola em análise, quer o pessoal técnico, quer sobretudo o pessoal docente continuam a destacar a fraca participação das famílias ciganas na vida escolar dos seus filhos e filhas ("só vêm à escola quando são chamados"), demonstrando desconhecimento face aos processos de desigualdade histórico-estrutural que marcam a presença das populações ciganas em contexto nacional (Mendes, 2007; Bastos, Correia e Rodrigues, 2007). Contudo, é evidente uma maior preocupação e um maior acompanhamento por parte das famílias entrevistadas, comparativamente às gerações anteriores. 
Nós íamos sozinhos para a escola, nem havia aquele acompanhamento de irem com os filhos, das reuniões, era diferente, acho que agora as coisas mudaram. [...]. Até porque eu tive que sair da escola para tomar conta do irmão que nasceu, eu devia ter oito anos quando saí, tinha feito o $4 .^{\circ}$ ano. [...]. Fui eu que o criei, por isso eu saí. O meu pai nunca proibiu de ir à escola, mas também nunca obrigou, "ah vai lá à escola". Gostava que a gente fosse, mas se a gente também não quisesse, para eles $3 .^{\circ}, 4 .{ }^{\circ}$ ano, saber ler e escrever, para mulheres é suficiente [mulher, 25-39 anos, 4. ${ }^{\circ}$ ano, desempregada].

Para Surdu e Switzer, (2015) a baixa taxa de participação escolar das crianças ciganas é parcialmente resultado do desinteresse parental na educação formal, do baixo envolvimento dos pais na vida escolar, da falta de recursos para sustentar as crianças na escola, das poucas aspirações educativas e da reduzida confiança no sistema escolar. Mas pouco se conhece sobre a relutância que alguns pais ciganos têm em interagir com o pessoal da escola e com outros pais, devido à assunção do estigma étnico e de uma falta de autoconfiança associada muitas vezes ao seu baixo status económico e educacional. A retórica da responsabilidade parental (ou da sua falta), juntamente com a atribuição de negligência e desinteresse em relação à escola, é transversal a um número de países diferentes, como foi evidenciado por Rostas e Kostka (2014).

Na escola em análise, formalmente, todas as crianças ciganas estavam integradas no $1 .^{\circ}$ ciclo (primeiros quatro anos de escolaridade). Os casos de abandono que existiam constituíam situações excecionais, que estavam a ser acompanhadas, quer por parte das escolas quer de outras instituições que atuavam no terreno, e as faltas letivas tinham diminuído consideravelmente nos últimos anos. Apesar de muitos jovens ciganos que conhecemos, de ambos os sexos, terem partilhado que sentiam uma desmotivação e desinteresse face à escola, continuavam a valorizar as relações de convivialidade que a escola possibilitava, com outros ciganos, mas também com jovens que não eram ciganos. Por exemplo, não raras vezes observámos que os jovens ciganos gostavam de permanecer no espaço escolar ou nas suas imediações apenas "pelo convívio", como referiam, mesmo em momentos em que as aulas já tinham terminado e em que podiam estar fora do meio escolar. Ao longo dos meses, fomos percebendo que os adolescentes ciganos tinham sentimentos positivos em relação à frequência escolar, destacando o facto de aqui terem a oportunidade de se relacionarem com outros jovens de forma mais livre do que no exterior, ou no bairro. Esta mesma ideia foi partilhada pelas suas famílias, como evidencia o seguinte testemunho:

[...] mas os alunos todos de lá, seja brancos, seja negros, apanharam os costumes deles. Falam igual a eles, falam à cigano, fazem juras à cigano! [homem, 40-64 anos, 7.․aㅁ ano, vendedor ambulante].

No que toca às aprendizagens formais, apesar de se terem verificado exceções, constatámos que a maioria tinha percursos escolares marcados pelo insucesso escolar - várias retenções, avaliações negativas a quase todas as disciplinas - , sendo este "insucesso" percebido por nós e não tanto pelos próprios alunos, que entendiam 
serem bem-sucedidos, na medida em que tinham níveis de escolaridade superiores à geração dos seus pais. Um aspeto a referir, que nos surpreendeu, foi a ocorrência de um "novo" tipo de "absentismo", uma vez que muitos jovens ciganos, de ambos os sexos, continuavam a faltar às aulas apesar de, ao contrário do passado, se encontrarem dentro dos recintos escolares. Por diversas vezes observámos a incapacidade do sistema escolar em assegurar que os jovens, não apenas os ciganos, frequentassem os tempos letivos, apesar de se encontrarem dentro do recinto escolar. Esta situação não se verificava no 1. ${ }^{\circ}$ ciclo, onde a dimensão das escolas e o contacto mais próximo com os professores e funcionários permitia um maior controlo dos alunos no espaço escolar.

Apesar das importantes mudanças que ocorreram nos últimos anos, globalmente, o insucesso escolar e os períodos de absentismo dos jovens ciganos continuavam a ser frequentes logo a partir do 2. . ciclo, conseguindo o AE em análise, através da diversificação da oferta formativa, reintegrar por mais alguns anos no sistema escolar muitos destes jovens. No entanto, as sucessivas quebras de continuidade dos estudos comprometiam objetivamente as trajetórias escolares destes alunos e a sua aquisição de competências. Os próprios professores passavam a encarar o seu trabalho apenas numa perspetiva de manutenção destes alunos no sistema educativo e não no sentido de aquisição de competências escolares.

À semelhança de outros contextos em que residem pessoas ciganas, as práticas de defesa identitária justificam o casamento precoce e a forte valorização da "pureza" da menina cigana, o que coloca diversos constrangimentos à continuidade dos percursos escolares das jovens a partir do início da adolescência, sendo raras as que continuavam integradas na escola depois dos 14, 15 anos de idade.

O pai chateava-se com ela, a explicar-lhe a nossa situação, que somos ciganos, a gente nãoé igual aos outros, somos diferentes. [...] Ela teve um ano que chumbou, no 7. ${ }^{\text {, ela }}$ já há dois anos que está no 7.ํㅡ, ou três porque ela tem chumbado. E o meu marido disse 'pronto, ela chumbou este ano, para o ano já faz 15 anos, ela está a levar a escola a brincar, não está a levar a sério porque ela não estuda, não passou, este ano chumbou'. Foi mais por causa disso também. As amigas dela também não a apoiavam nada e era uma distração que era fora do normal [...] [mulher, 25-39 anos, 4. ․ ano, domésti$\mathrm{ca} /$ venda ambulante].

Para Bereményi e Carrasco (2015) o casamento precoce está a aumentar enquanto nova estratégia para fazer face à crise socioeconómica, sendo, para estes autores, uma forma de rentabilizar benefícios sociais e oportunidades económicas através do reforço da solidariedade familiar e intraétnica. No presente contexto escolar, observou-se que quase todos os jovens ciganos deixavam de frequentar a escola por volta das idades indicadas, sendo "o casamento" precoce o motivo apontado pelos técnicos dos projetos e serviços locais entrevistados no âmbito desta pesquisa.

No que se refere à organização escolar, constatou-se a concentração de alunos ciganos nas mesmas turmas, e até em algumas escolas dos AE. No caso deste AE, tratava-se de turmas que apresentavam piores resultados académicos e em que os professores depositavam poucas expetativas e apontavam maiores dificuldades a nível do comportamento e da indisciplina em sala de aula. 
Vários fatores pareciam confluir para a concentração de alunos ciganos, cruzando as realidades escolares e as vivências de bairro, havendo uma tendência para que a segregação espacial e social se repercutisse em termos de segregação escolar (Parra, Álvarez e Gamella, 2017). Na escola básica do 1.ํㅜ ciclo do AE aqui em análise, o número de crianças matriculadas tem vindo a decrescer de ano para ano, com muitas famílias, a maioria não ciganas, a optarem por matricular os seus filhos noutras escolas, recorrendo para esse efeito a diferentes estratégias para contornar as regras de atribuição de vagas. Por falta de alunos, no ano em que realizámos este estudo, não foi aberta uma turma para a frequência do $1 .^{\circ}$ ano e, por entre corredores entre professores e auxiliares, alvitrava-se que a escola deveria ser fechada por ser "um gueto". Dos 49 alunos que frequentavam a escola no 1.. trimestre do ano letivo de 2014/2015, 29 eram de origem cigana, 12 raparigas e 17 rapazes, constituindo a maioria dos alunos. De salientar ainda que dos 20 alunos que não eram ciganos, três tinham origem identificada pela escola como sendo "africana". O número de alunos ciganos era, portanto, desproporcional em relação à composição social da envolvente à escola. Por vezes a concentração escolar de alunos ciganos em escolas traduz um processo de transferência social mobilizado pelos pais dos alunos não ciganos para outras escolas (Parra, Álvarez e Gamella, 2017: 44).

$\mathrm{Na}$ opinião dos professores que ali trabalhavam, apesar da boa relação com e entre os alunos, independentemente da sua origem étnica, a concentração de alunos ciganos nesta escola é percebida como muito negativa e tem influência no sucesso dos percursos escolares dos alunos em geral. Com efeito, alguns estudos indicam que os resultados escolares poderão ser mais positivos em ambientes de aprendizagem multicultural e multiétnica, em que os programas são igualmente estabelecidos para todos (Abajo e Carrasco, 2004), situação que não se verificava nesta escola, dada a desproporcionada concentração de alunos ciganos. Consideramos elucidativo o facto de, coloquialmente, as instituições que intervinham no terreno não raras vezes se referirem a esta escola como a "escola dos ciganos".

Vejamos o caso particular de uma turma do 3.․ano do ensino básico desta escola, turma que tivemos oportunidade de observar e acompanhar, na qual a maioria dos alunos eram ciganos. Dos 20 alunos matriculados na turma, 13 foram identificados pela escola como de origem cigana. Mas, nas aulas a que assistimos, apenas conhecemos 16 alunos, nove dos quais de origem cigana. A explicação dada para a ausência de quatro alunos ciganos prendia-se com a desatualização das listas de alunos, tratando-se de casos que teriam pedido transferência. O intervalo de idades dos alunos é significativo para uma turma do $3 .^{\circ}$ ano, variando entre os oito e os 11 anos, alguns alunos já com três retenções no 1.. ciclo. Esta diferença de idades espelhava-se na aparência das crianças, algumas fisicamente muito mais desenvolvidas do que as outras mais novas. Acresce o facto de muitos dos alunos da turma, apesar de inscritos no 3. ${ }^{\circ}$ ano, no quotidiano das aulas, seguirem livros e materiais escolares dos anos anteriores a Língua Portuguesa e a Matemática. Num caso concreto, verificou-se que uma aluna cigana estava ainda a aprender os conteúdos do 1.ํo ano a Língua Portuguesa, não conseguindo ler e escrever de forma autónoma, passando parte do tempo a realizar cópias. Observámos que esta aluna tinha dificuldade em reconhecer todas as letras do abecedário, quer quando a 
professora escrevia com letra "à mão" no quadro, quer quando copiava um texto de um livro com letra "de máquina".

No caso desta turma, apesar de terem transitado para o 3. ${ }^{\circ}$ ano de escolaridade, sete alunos ciganos não tinham alcançado os objetivos mínimos do ano transato, acompanhando, à data do estudo, conteúdos programáticos do 2.ํano. Esta medida, que visa fazer face ao abandono e insucesso escolar, recomendada como boa prática pela OCDE, nesta turma em particular, parecia oferecer diversos constrangimentos à professora, que expressava ter dificuldade em acompanhar "tantos" alunos nesta situação. Durante a observação das aulas o panorama revelou-se mais grave, uma vez que constatámos que alguns destes alunos praticamente não sabiam ler ou escrever e que os livros e materiais com que efetivamente trabalhavam correspondiam ao 1. ․ ano de escolaridade. Como é referido por Parra, Álvarez e Gamella (2017) o "atraso" educativo (com repetições de ano, com o não conseguir atingir os objetivos de aprendizagem) começa na maior parte das vezes no $1 .{ }^{\circ}$ ciclo (equivalente ao ensino primário espanhol), o que se vai repercutir com maior intensidade no ciclo de estudos a seguir, com um "atraso" acumulado de aprendizagens que ficaram por fazer. De acordo com Afonso (2003: 44) as estratégias em que assentam as políticas de diversificação e de hierarquização da oferta educativa pública portuguesa contribuem para "escamotear velhas fórmulas de indução discriminatória e classista, que parecem estar de novo a ser reintroduzidas no sistema educativo português, atribuindo exclusivamente à responsabilidade individual dos sujeitos as supostas escolhas e opções relativas aos seus percursos de escolarização e formação".

Em geral, alguns alunos desta turma do 3. ${ }^{\circ}$ ano, e não apenas os alunos ciganos, tinham dificuldades a nível da leitura e da realização de cálculos matemáticos. A professora confirmou a nossa observação, referindo que, com exceção de dois ou três casos, os alunos tinham poucos conhecimentos para o nível de ensino que frequentavam. Para a professora desta turma desde o $1 .^{\circ}$ ano - e apesar de se afigurar como uma "turma de nível", embora não nomeada como tal, pois, era por demais evidente o desfasamento dos seus alunos em relação aos alunos do 3.ำ ano de outras escolas do AE. Tal sucedia por se tratar de uma escola e de uma turma "muito desafiante ao nível das aprendizagens" e com alguns problemas de "disciplina" em sala de aula. A professora referiu ainda que não existia um aluno que "se destacasse" positivamente dos restantes pelo seu desempenho ou comportamento em sala de aula, dando como exemplo o caso de uma aluna cigana que tinha sido transferida de outro AE e que, apesar de ter chegado com uma avaliação escolar muito positiva, já se "estava a perder" por causa de a turma "ser muito complicada". Para a professora as atitudes comportamentais de destabilização e de desafio que os seus alunos evidenciavam, particularmente os alunos ciganos, eram entendidas como a forma "que eles têm" de superar as dificuldades de aprendizagem que estavam a sentir porque "eles não gostam de não saber", era devido a uma "insegurança", ao "medo de falhar" e ao "não querer dar parte de fraco".

O foco nas questões comportamentais e nas (in)capacidades dos alunos constituía um argumento transversal aos discursos dos professores, verificando-se uma quase ausência de reflexão em relação, por exemplo, à adequação dos conteúdos 
programáticos, à forma como lecionavam as aulas ou até em relação às suas próprias condutas e atitudes para com os seus alunos. Aqui e à semelhança do que acontece em muitos países europeus, a cultura, a história e a língua romani estão (normalmente) ausentes da escola (Kyuchukov, 2000) não se verificando também uma diversidade de abordagens e de instrumentos pedagógicos (Cortesão, 1995).

Em geral, os professores evidenciavam uma imagem claramente estereotipada em relação aos alunos ciganos, observando-se uma sobrevalorização quanto às capacidades destes para as artes (música, dança, desenho), por contraposição às restantes disciplinas (sobretudo Português, mas também Matemática). Ficou evidente que as expetativas dos professores em relação aos alunos ciganos eram, quase sempre, muito baixas, em todos os níveis de ensino, sendo evidente o "efeito Pigmalião" (efeito Rosenthal) e a profecia que inevitavelmente acaba por se autorrealizar (Gomes, 1987; Merton, 1964).

Apesar das observações quase sempre negativas por parte de professores quanto ao desempenho escolar dos estudantes ciganos, em termos de dinâmica em sala de aula, em todas as turmas do AE que acompanhámos, observámos que as crianças e jovens ciganos eram mais participativas do que os seus colegas e que eram dos que mais interagiam com os professores. Nem todos os professores percebiam esta caraterística como positiva, alguns referiam que este era um fator de desestabilização, percebendo estas condutas como uma grande resistência e desafio à sua autoridade, o que, claramente, limitava a sua capacidade de trabalhar com estas crianças e jovens.

\section{Notas conclusivas}

As crianças e jovens ciganos estão mais presentes nas escolas públicas portuguesas mas subsistem elevados casos de insucesso escolar e abandono precoce, o que revela a incapacidade de as medidas compensatórias, só por si, enfrentarem este desafio de concretização da escolaridade obrigatória, situação que persiste e que continua por resolver na sociedade portuguesa em relação aos cidadãos ciganos. Por outro lado, a grande maioria dos alunos ciganos que alcança o $3 .^{\circ}$ ciclo, particularmente as raparigas, não o faz através do ensino regular, mas sim por via de políticas de educação compensatórias a que os $\mathrm{AE}$ aderem para possibilitar, precisamente, a continuidade do percurso escolar dos alunos ciganos, nomeadamente das raparigas. Ou seja, tal acontece sobretudo através de medidas de compensação educativa, que acabam por ser medidas educativas segregadoras (Parra, Álvarez e Gamella, 2017). Destacamos, particularmente, o caso dos percursos curriculares alternativos (PCA) e do Programa Integrado de Educação e Formação (PIEF), ofertas formativas que as pessoas contactadas no terreno referiram visar os alunos ciganos. Trata-se de turmas em que a percentagem de alunos ciganos chega a rondar os $85 \%$. Note-se que, de acordo com o que nos foi transmitido, os AE não podem constituir turmas só com alunos ciganos sem autorização do Ministério da Educação, sendo, em regra, os pedidos rejeitados.

Em relação a outras medidas, como o ensino à distância, ainda não são conhecidos os seus reais impactos e resultados. Embora as famílias considerem esta 
modalidade de ensino positiva, na prática os jovens sentem falta de apoio, e resta apurar se não consiste em mais uma nova forma de segregação dos jovens ciganos, "retirando-os" dos contextos escolares reais e de convivência multiétnica.

Em suma, apesar dos projetos e programas de apoio social e educativo acionados ao longo do tempo no território em análise, tal revela-se ainda insuficiente para fomentar a frequência escolar e o sucesso educativo. A segregação social e espacial que marca os contextos residenciais destes alunos prolonga-se, ainda que de forma mitigada, no espaço escolar. A concentração de alunos ciganos na mesma turma ou escola limita em grande medida a qualidade do ensino. Na turma em análise observámos um processo de atrasos de aprendizagem acumulados e que começam no 1.. ciclo e se prolongam ao longo de todo o percurso escolar, quase sempre marcado por insucesso escolar, repetições, não aquisição de competências esperadas para o ano letivo, o que acaba por confluir no encaminhamento para medidas de compensação educativa. A segregação social e espacial reflete-se também em formas de segregação escolar, seja pelas práticas das escolas, por via da constituição de turmas "específicas" para ciganos, seja pelo encaminhamento para medidas educativas compensatórias mas cujas práticas pedagógicas e processos educativos não são avaliados e questionados do ponto de vista da sua aplicação a diferentes contextos sociais e culturais. De facto, importa ter em conta o "arco-íris cultural" (Cortesão, 1995) que os estudantes de uma sala de aula representam, emergindo a necessidade de implementação de novas atitudes e práticas pedagógicas.

\section{Referências bibliográficas}

Abajo, José Eugenio, e Silvia Carrasco (2004), Experiencias y Trayectorias de Éxito Escolar de Gitanas y Gitanos en España. Encrucijadas sobre Educación, Género y Cambio Cultural, Madrid, Ministerio de Educación Cultura y Deporte, Centro de Investigación y Documentación Educativa, Ministerio de Trabajo e Inmigración, Instituto de la Mujer.

Abajo, José Eugenio, e Silvia Carrasco (2011), “La situación escolar del alumnado de minorias étnicas: el modelo explicativo ecológico-cultural de John Ogbu 1", Recerca, 11, pp. 71-92.

Afonso, Almerindo Janela (2003), “Estado, globalização e políticas educacionais: elementos para uma agenda de investigação", Revista Brasileira de Educação, 22, pp. 35-46.

Bastos, José, André Correia, e Elsa Rodrigues (2007), Sintrenses Ciganos. Uma Abordagem Estrutural-Dinâmica, Lisboa, ACIDI e Câmara Municipal de Sintra.

Bereményi, Bálint Ábel, e Sílvia Carrasco (2015), “Interrupted aspirations: research and policy on Gitano education in a time of recession, in Spain", Intercultural Education, 26 (2), pp. 1-12.

Bourdieu, Pierre, e Jean-Claude Passeron (1970), La Reproduction. Éléments pour Une Théorie du Système d'Enseignement, Paris, Minuit.

Brockmann, Michaela (2011), "Problematising short-term participant observation and multi-method ethnographic studies", Ethnography and Education, 6 (2), pp. 229-243. 
Casa-Nova, Maria José (2009), Etnografia e Produção de Conhecimento. Reflexões Críticas a Partir de Uma Investigação com Ciganos Portugueses, Lisboa, ACIDI.

Cerletti, Laura Beatriz (2011), “En torno a la escolarización infantil: un enfoque etnográfico sobre prácticas cotidianas y sentidos en disputa", Revista Inter-Legere, 9, pp. 252-269.

Cordeiro, Graça Índias, Luís Vicente Baptista, e António Firmino da Costa (orgs.) (2003), Etnografias Urbanas, Oeiras, Celta Editora.

Cortesão, Luísa (1995), “Reflexões críticas sobre a educação de crianças ciganas”, em Luísa Cortesão e Fátima Pinto (orgs.), O Povo Cigano. Cidadãos na Sombra Processos Explícitos e Ocultos de Exclusão, Porto, Edições Afrontamento, pp. 27-36.

Denzin, Norman, e Yvonna Lincoln (2000 [1994]), “Introduction: the discipline and practice of qualitative research", em Norman Denzin e Yvonna Lincoln (orgs.), Handbook of Qualitative Research, Thousand Oaks, CA, Sage, pp. 1-28.

DGEEC - Direção Geral de Estatísticas da Educação e Cência (2018), Perfil Escolar da Comunidade Cigana 2016/17, Lisboa, DGEEC.

Feinberg, Walter (2015), “Critical pragmatism and the appropriation of Ethnography by Philosophy of Education", Studies in Philosophy and Education, 34, pp. 149-157.

Fernandes, Luís (1998), O Sítio das Drogas, Lisboa, Editorial Notícias.

Gomes, Carlos Alberto (1987), “A interacção selectiva na escola de massas”, Sociologia, Problemas e Práticas, 3, pp. 36-49.

Hammersley, Martyn, e Paul Atkinson (2007), Ethnography. Principles in Practice, Londres, Routledge.

INE - Instituto Nacional de Estatística (2011), Censos 2011 - Resultados Definitivos, Lisboa, INE.

Kyuchukov, Hristo (2000), “Transformative education for Roma (Gypsy) children: an insider's view", Intercultural Education, 11, pp. 273-280.

Lopes, Daniel Seabra (2008), Deriva Cigana. Um Estudo Etnográfico sobre os Ciganos de Lisboa, Lisboa, Imprensa de Ciências Sociais.

Magano, Olga (2010), Tracejar Vidas Normais. Estudo Qualitativo sobre a Integração Social de Indivíduos de Origem Cigana na Sociedade Portuguesa, Lisboa, Universidade Aberta, tese de doutoramento em Sociologia.

Magano, Olga, e Maria Manuela Mendes (2014), "Ciganos e políticas sociais em Portugal”, Sociologia, Revista da Faculdade de Letras da Universidade do Porto, número temático “Ciganos na Península Ibérica e Brasil: Estudos e Políticas Sociais”, pp. 15-35.

Magano, Olga, e Maria Manuela Mendes (2016), “Constrangimentos e oportunidades para a continuidade e sucesso das pessoas Ciganas", Revista Configurações, número temático "Ciganos e Educação", pp. 8-26.

Magnani, José Guilherme Cantor (2002), “De perto e de dentro: notas para uma etnografia urbana", Revista Brasileira de Ciências Sociais [online], 17 (49), pp. 11-29.

Mattos, Carmem Lúcia Guimarães (2011), “A abordagem etnográfica na investigação científica”, em Carmem Lúcia Guimarães Mattos e Paula Almeida Castro (orgs.), Etnografia e Educação. Conceitos e Usos [online], Campina Grande, Editora da Universidade Estadual da Paraíba, pp. 49-83.

Mendes, Maria Manuela (2007), Representações Face à Discriminação. Ciganos e Imigrantes Russos e Ucranianos na Área Metropolitana de Lisboa, Lisboa, Instituto de Ciências Sociais, tese de doutoramento em Ciências Sociais. 
Mendes, Maria Manuela, Olga Magano, e Pedro Candeias (2014), Estudo Nacional sobre as Comunidades Ciganas, Lisboa, Alto Comissariado para as Migrações.

Merton, Robert King (1964), Teoría y Estructura Sociales, México, DF, Fondo de Cultura Económica.

Nicolau, Lurdes (2010), Ciganos e Não Ciganos em Trás-os-Montes. Investigação de Um Impasse Interétnico, Vila Real, Universidade de Trás-os-Montes e Alto Douro, tese de doutoramento em Ciências Sociais.

Ogbu, John Uzo (1981), “School ethnography: a multilevel approach”, Anthropology $\mathcal{E}$ Education Quarterly, 12 (1), pp. 3-29.

Parra, Iván, Arturo Álvarez, e Juan Francisco Gamella (2017), “Un conflicto silenciado: procesos de segregación, retraso curricular y abandono escolar de los adolescentes gitanos", Revista de Paz y Conflictos, 10 (1), pp. 35-60.

Rostas, Iulius, e Joanna Kostka (2014), “Structural dimensions of Roma school desegregation policies in Central and Eastern Europe", European Educational Research Journal, 13 (3), pp. 268-281.

Santos, Marta, Ricardo Romano, Lia Cavaleiro, e Margarida Antunes (2008), “Etnia cigana nos bairros municipais de Lisboa: recenseamento e reflexões", em Alexandra Castro, Maria Santos, João Paulo Marques e Helena Torres (orgs.), Atas do Seminário Internacional - Ciganos, Territórios e Habitat. Lisboa, ISCTE, pp. 147-167.

Setti, Federica (2015), “The implications of 'naming' on Roma and Sinti right to education and social inclusion: an ethnography of education among a Sinti family network", Intercultural Education, 26 (2), pp. 114-130.

Sigona, Ferdinando (2009), Ethnography of the 'Gypsy Problem' in Italy. The Case of Kosovo Roma and Ashkali in Florence and Venice, Oxford, Oxford Brookes University, tese de doutoramento.

Silva, Pedro, Octávio Sacramento, e Vera Mendonça (2015), “Proximidade, reflexividade e crítica: o lugar da etnografia na intervenção social", Cuadernos de Trabajo Social, 28 (1), pp. 25-35.

Surdu, Laura, e Furugh Switzer (2015), “Reading tales: an informal educational practice for social change", ZEP - Zeitschrift für internationale Bildungsforschung und Entwicklungspädagogik, 38 (1), pp. 24-28.

Wacquant, Loïc (2014), “Marginality, ethnicity and penality in the neo-liberal city: an analytic cartography", Ethnic and Racial Studies, 37 (10), pp. 1687-1711.

Maria Manuela Mendes. Investigadora integrada no Iscte - Instituto Universitário de Lisboa, Centro de Investigação e Estudos de Sociologia (Cies_Iscte), Lisboa, Portugal; professora auxiliar na FAUL, Universidade de Lisboa. E-mail: mamendesster@gmail.com

Olga Magano. Professora auxiliar na Universidade Aberta (UAb); Investigadora integrada no Iscte - Instituto Universitário de Lisboa, Centro de Investigação e Estudos de Sociologia (Cies_Iscte), Lisboa, Portugal. E-mail: Olga.Magano@uab.pt 
Ana Rita Costa. Doutoranda em Antropologia, Iscte - Instituto Universitário de Lisboa, Lisboa, Portugal; Centro em Rede de Investigação em Antropologia (CRIA); E-mail: Ana.Rita.Costa@iscte-iul.pt

Receção: 18 de maio 2018 Aprovação: 16 de junho de 2018 